\title{
Schwann cell-derived factors support serotoninergic neuron survival and pro- mote neurite outgrowth
}

\author{
R. Pellitteri, A. Zicca, G.L. Mancardi', T. Savio, and A. Cadoni
}

Department of Experimental Medicine (Di.Me.S.) and 'Department of Neurological Sciences, University of Genoa, Via De Toni 14, 16132 Genoa, Italy

Accepted: 22/5/01

Key words: Schwann cells, serotoninergic neurons, 5-HT neurons, growth factors, immunocytochemistry, morphometry

\section{SUMMARY}

During embryogenesis and the postnatal period, neurons and glia interact in the development and differentiation of specific populations of nerve cells. Both in the peripheral (PNS) and in the central nervous system (CNS), glial cells have been shown in various experimental conditions to constitute a favorable substrate for neural adhesion, neural polarity, shape and axonal extension, while numerous soluble molecules secreted by neurons influence the survival and differentiation of the glial cells themselves. The aim of the present work was to investigate the influence of postnatal Schwann cells (SC) on embryonic serotoninergic (5-HT) neurons of the raphe, in order to study the possible influence of the peripheral glia on the CNS neurons. Cultures of SC from sciatic nerve of postnatal rats and neurons from rat embryonic rhombencephalon were successfully established and cells were immunocytochemically characterized. The number of 5-HT neurons, and the number and length of their branches were quantified in the cultures of 5-HT neurons, in cultures added with Nerve Growth Factor (NGF) and Insulin-like Growth Factor I (IGF-I), in co-cultures with SC and in cultures added with conditioned medium obtained from SC cultures.
The results indicated that SC have the capacity to promote the survival and growth of 5-HT neurons in culture, and that this activity is mediated by soluble factors. Although the precise nature and mechanism of action of the growth factor or factors produced by SC in the presence of 5-HT neurons was not identified, our results add more data on the possible activity of the peripheral glia in promoting and enhancing the survival and outgrowth of the CNS neurons.

\section{INTRODUCTION}

During embryogenesis and the postnatal period neurons and glia in the central nervous system (CNS) and the peripheral nervous system (PNS) interact on the survival, maturation, migration and differentiation of specific neural and glia populations of cells. The possible mechanisms involved in the mutual relationship between neurons and glia have been extensively investigated. In the CNS, in fact, astrocytes have been shown to produce a wide variety of trophic factors affecting the development and survival of different neuronal cell types (Barde, 1989; Knusel et al., 1990; Hyman et al., 1991; Mayer et al., 1993; Beck et 
al., 1993; Hyman et al., 1994; Murphy et al., 2000), the morphology of isolated neurons in vitro (Banker et al., 1980; Muller and Seifert, 1982; Hatten et al., 1988) and the function of neurons by regulating their size, synthesis of transmitter enzymes and neuritic outgrowth (Purves, 1988; Snider and Johnson, 1989; Franke et al., 2000). Conversely, the reciprocal influence of neurons and glia was established by the demonstration that trophic factors produced by neurons significantly promote the proliferation, morphology, maturation and survival of astroglia and oligodendroglia cells (Hatten, 1985).

A close interaction between neuronal and glial cells also occurs in the PNS. Nerve growth factors support the survival of cultured sympathetic neurons (Barde et al., 1982), and members of the neurotrophin gene family are expressed by developing sensory and motor neurons (Friedman et al., 1991; Russel et al., 2000). Schwann cells (SC) produce neurotrophic factors that activate specific cell surface receptors, which start a cascade of intracellular events modifying neuronal morphology, survival and/or functional capacity (Yuen et al., 1996; Munson et al., 1997).

The close interaction between nerve cells and glial cells is present during the adult lifetime (Mirsky et al., 1999) and probably trophic substances are continuously produced acting as factors necessary for normal neuronal function and survival (Levi-Montalcini, 1987; Ruit and Snider, 1991; Longo et al., 1992; Holtzman et al. 1995, Friedman et al., 1999). The amount of trophic factors are likely to increase during degenerative and especially regenerative processes of the nervous tissue. For instance, Nerve Growth Factor (NGF) mRNA and Brain-derived Neurotrophic Factor (BDNF) mRNA are upregulated after axotomy of the peripheral nerve at the lesion site and in the distal stump, at the same time when SC express on their surface a large amount of the p75 low affinity receptor for neurotrophins. Considering the reparative capacities of the PNS, and the great abundance of growth factors produced by SC (Frostick et al., 1998), it has been suggested that SC might influence repair and regeneration also in the CNS (Xu et al., 1995).

Studies by Collier et al. $(1993,1999)$ have shown that SC are able to secrete a diffusible molecule or a combination of molecules that influence the sur- vival and axonal outgrowth of embryonic dopaminergic neurons. These data have induced us to verify if postnatal SC have the capacity to influence in the same way the survival and the neuronal branching of other central monoamine neurons. In CNS, monoamine neurons are distributed in different areas, such as the locus coeruleus (containing norepinephrine), the substantia nigra (containing dopamine) and the raphe nuclei (containing serotonin) (Dahlstrom and Fuxe, 1964).

In this study, we determined the relation between SC and serotoninergic (5-HT) neurons in culture.

The results showed that SC significantly increased the number and the dendritic sprouting of 5-HT neurons, and that this effect was probably mediated by soluble factors.

\section{MATERIALS AND METHODS}

\section{Neuronal Cultures}

Cell suspensions were prepared from rat embryos (crown-rump length 10-11 mm). Pregnant female rats (Sprague Dawley, Nossan) were anaesthetized in ether. The embryos were removed by caesarian section and placed in cold Leibowitz L-15 medium $\left(4^{\circ} \mathrm{C}\right)$ where all dissection processes were carried out. The rostral rhombencephalon, which contains developing 5-HT neurons from the raphe complex (Konig et al., 1988), was dissected out and pieces of tissue were incubated for 6 min in $0.1 \%$ trypsin in a solution of $0.1 \mathrm{M}$ phosphate-buffered saline (PBS), $\mathrm{pH} 7.4$, containing $0.02 \%$ EDTA at $37^{\circ} \mathrm{C}$. Then $0.001 \%$ deoxyribonuclease was added and the cells were centrifuged; the supernatant was removed and the cells were resuspended and triturated through a fire-polished Pasteur pipet in $1 \mathrm{ml}$ of triturating solution $[1 \%$ bovine serum albumine (BSA), $0.001 \%$ DNAse, $0.1 \%$ soybean trypsin inhibitor in PBS].

Dissociated cells were then plated on $13 \mathrm{~mm}$ diameter poly-L-lysine (PLL; $10 \mu \mathrm{g} / \mathrm{ml}$ ) coated glass coverslips at a final density of $2 \times 10^{4}$ cells/coverslip and maintained in Dulbecco's modified Eagle's medium (DMEM) supplemented with $10 \%$ fetal calf serum (FCS), 2 mM L-glutamine, penicillin $(50 \mu \mathrm{g} / \mathrm{ml})$ and streptomycin $(50 \mathrm{U} / \mathrm{ml})$. Contaminating non-neuronal cells were reduced by treatment with the antimitotic agent cytosine arabinoside $\left(10^{-5} \mathrm{M}\right)$ added $24 \mathrm{~h}$ after the dissection. 
Cells were incubated in this medium for a week with two medium changes. Some wells containing neurons were treated with NGF 2.5 S (Boehringer Mannheim, $50 \mathrm{ng} / \mathrm{ml}$ ) or IGF I (Insulin-like Growth Factor, somatomedin C, Boehringer Mannheim, 10 $\mathrm{ng} / \mathrm{ml})$.

\section{Schwann cell cultures}

$\mathrm{SC}$ were isolated from the sciatic nerves of 2-day old rat pups (P2) using the procedure described by Brockes et al. (1979). Briefly, sciatic nerves were removed and treated with $0.1 \%$ collagenase and $2.5 \%$ trypsin in DMEM, mechanically dissociated by trituration and filtration through a $150 \mu \mathrm{m}$ nylon mesh. Cells were resuspended in fresh complete medium and plated at a density of $5 \times 10^{6}$ cells. Cytosine arabinoside $\left(10^{-5} \mathrm{M}\right)$ was added 24 $\mathrm{h}$ after initial plating to reduce the number of dividing fibroblasts. To eliminate fibroblasts that survived the antimitotic agent, SC cultures were treated with monoclonal antibody Anti-thy 1.1 (Serotec) and a rabbit complement (Cedarlane Lab.). Fibroblast contamination was minimal after this stage (about 1.5\%).

\section{5-HT Neuron-SC co-cultures}

Dissociated SC at a final density of $1.5 \times 10^{4}$ cells/coverslip were plated onto coverslips containing 5-HT neurons as previously described.

Both neuronal cultures and co-cultures were kept at $37^{\circ} \mathrm{C}$ with $5 \% \mathrm{CO}_{2}$ for a week and then were processed for immunocytochemical staining.

\section{Preparation of conditioned medium}

The conditioned medium (CM) was obtained from $\mathrm{SC}$ cultures grown in DMEM supplemented with $10 \%$ FCS, 2 mM L-glutamine, penicillin/streptomycin. The cultures were washed several times with fresh medium. After 3 days, the CM was removed from the cultures and immediately passed through a membrane filter $(0.2 \mu \mathrm{m}$ pore diameter) to remove cells and debris. The retained medium was resuspended in fresh medium and added to the serotoninergic neuronal cultures.

\section{Immunocytochemistry}

Individual populations of cells were identified by immunocytochemical procedures. The cells were fixed by exposure to $4 \%$ paraformaldehyde in $0.1 \mathrm{M}$ PBS for 30 minutes. After washing in PBS, the cell membranes were permeabilized with $5 \%$ normal goat serum (NGS) in PBS containing $0.1 \%$ Triton X-100 (PBS-Triton) at room temperature for 15 min. This step was followed by incubation overnight at $4^{\circ} \mathrm{C}$ in the primary antibody, a polyclonal anti-serotonin (Incstar) used at the concentration 1:100. Co-cultures were incubated overnight both with anti-serotonin and with monoclonal antiNerve Growth Factor receptor (anti-NGFr, Boehringer Mannheim) at the concentration 1:10 which reacts with the low affinity NGF-receptor. All primary antibodies were diluted in PBS-Triton containing $1 \%$ NGS. After washing in PBS, coverslips were incubated in secondary antibody, [dichlorotriazihyl amino (DTAF) labelled anti- rabbit antibody (Jackson Immuno Res. Lab.) at the concentration 1:50 to visualize the polyclonal primary antibody (anti-serotonin) and tetramethyl rhodamine isothiocyanate (TRITC) labelled antimouse antibody (Jackson Immuno Res. Lab.) at the concentration 1:50 to visualize monoclonal antibody (NGFr)] in PBS-Triton containing 1\% NGS, at $4^{\circ} \mathrm{C}$ for $30 \mathrm{~min}$. Coverslips were washed and mounted in PBS/glycerol (50:50) and placed on glass microscope slides.

In all instances negative controls without primary antibody were performed.

\section{Morphometric study}

Coverslips were analysed on a Leitz fluorescent microscope and 5-HT positive neurons were counted over the entire coverslips. Moreover, for each 5HT positive neuron, the number of neuronal branches and total length of fibers were determined using image analysis. For each culture condition, a minimum of 10 experiments were carried out, the means were subsequently obtained and data were assessed by statistical analysis: fiber length data were tested by the Friedman Test and the number of neurons was tested by the Wilcoxon's Test.

\section{RESULTS}

Effects of growth factors on survival and branching of serotoninergic neurons

Surviving 5-HT neurons kept for 7 days under previously described culture conditions, increased after treatment with NGF or IGF-I. Figure 1 shows the clear difference between controls and trophic 


\section{Number of neurons}

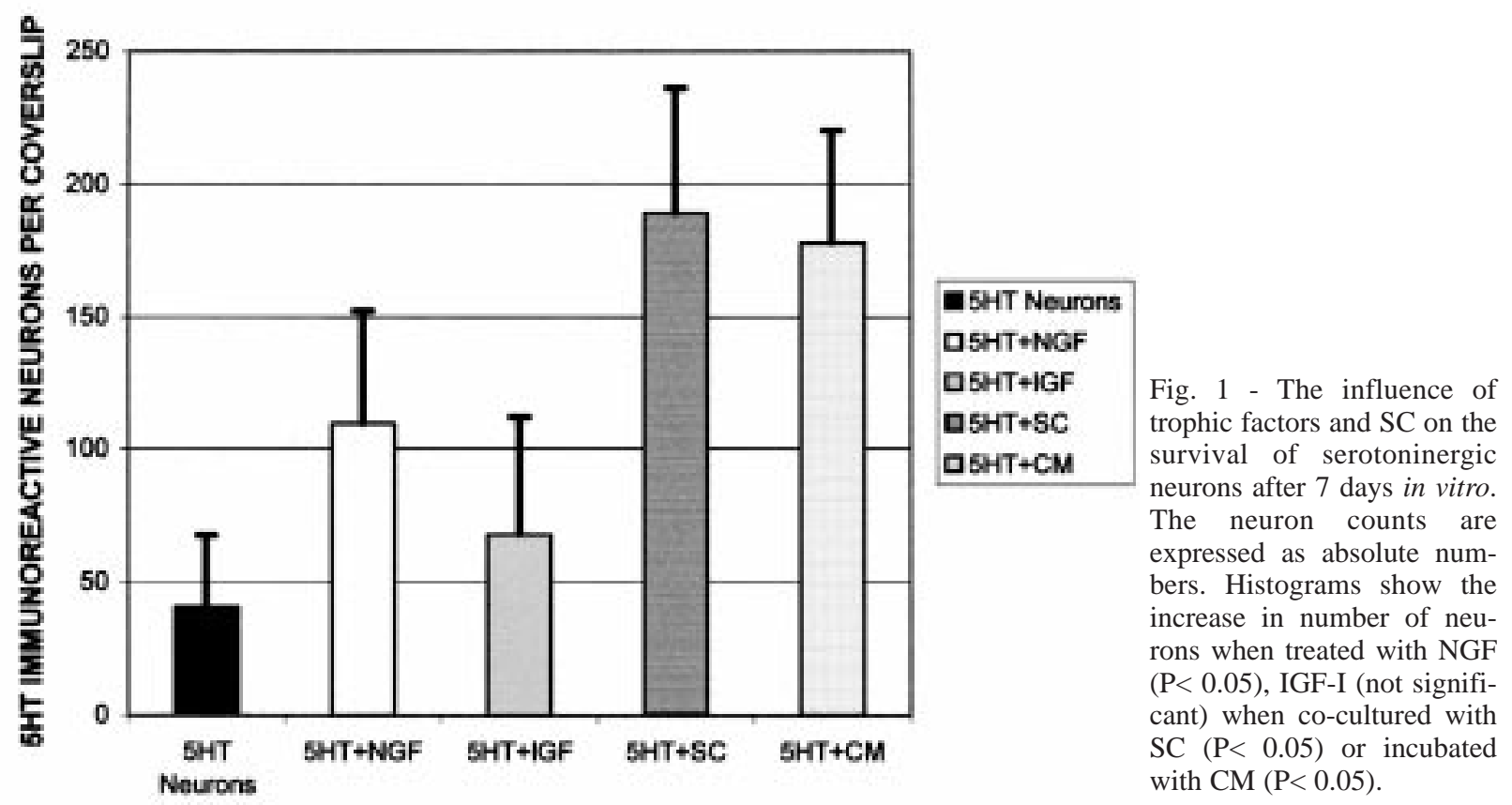

factor-treated cultures. In NGF-treated cultures, we obtained a higher number of 5-HT neurons as compared to control (109 vs 40 per coverslip, $\mathrm{P}<0.05$ ) while in IGF-I-treated neurons the increase ( 68 per coverslip) was not significant. These results demonstrate that survival of the serotoninergic neurons is enhanced in the presence of specific growth factors, although the increase in number of neurons reached statistical significance only when NGF was added to the culture.

\section{Branching length}

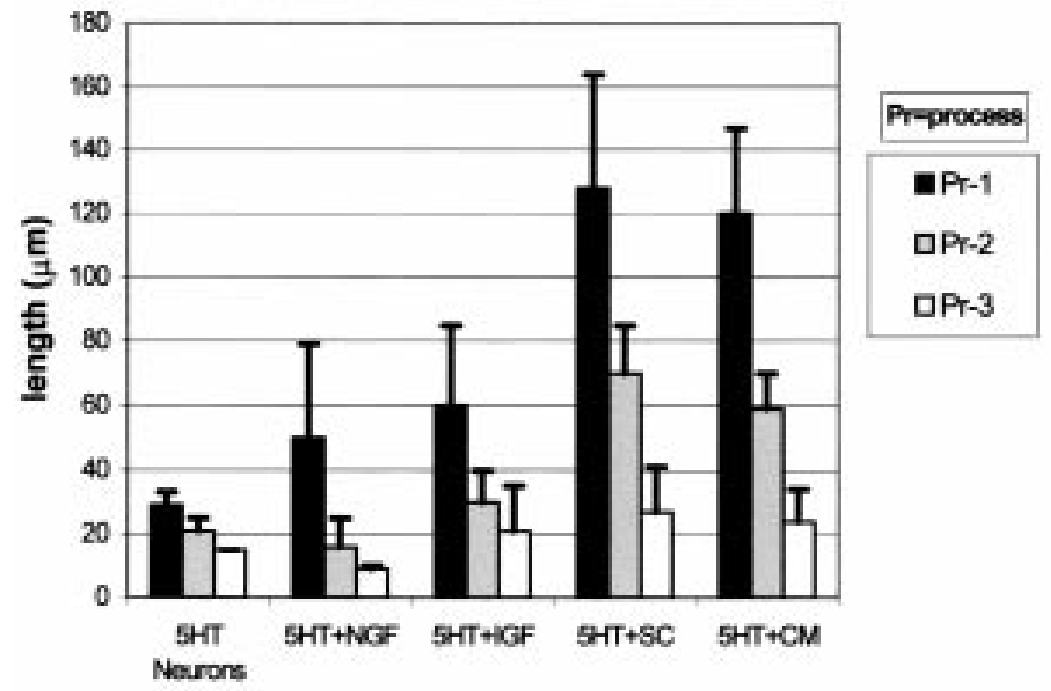

Fig. 2 - Histograms show the length of processes (Pr) exhibited by serotoninergic neurons under each culture condition. Control cultures presented short processes by contrast to long processes exhibited by serotoninergic neurons in the presence of NGF, IGF-I, SC $(\mathrm{P}<0.05)$ or incubated with CM $(\mathrm{P}<0.05)$. 
Computerized measurements of immunocytochemically stained 5-HT neurons indicated that these cells exposed to trophic factors, such as NGF or IGF I, exhibited a greater complexity and degree of neuritic and dendritic outgrowth than in controls. As shown in Figures 2, 3A and 4A, in control cultures serotoninergic neurons exhibited short processes $\left(\operatorname{Pr}_{-1}=29 \mu \mathrm{m}\right)$ whereas in the presence of NGF (Fig. 2, 3B and 4B) or IGF-I (Fig. 2, 3C and 4C), the 5-HT neurons presented an increase in dendritic length, branching and number of primary dendrities with an average length of $50 \mu \mathrm{m}$ if treated with NGF and about $60 \mu \mathrm{m}$ if treated with IGF-I.

These findings demonstrate the capability of NGF and IGF-I to induce greater axonal and dendritic branching showing more branch points than control cultures.

Schwann cell-derived factors stimulate serotoninergic neuron survival and branching

We found a clear increase in the number of surviving 5-HT neurons when embryonic rhombencephalic neurons were co-cultured with primary $\mathrm{SC}$ for 7 days.

The number of neurons grown in the presence of SC was more than four times as high as controls (189 vs 40 per coverslip, $\mathrm{P}<0.05$ ). The co-cultures with SC had a higher number of neurons than the cultures treated with NGF or IGF-I but this increase did not reach statistical significance. These data suggest that, in our experimental conditions, SC contribute to promote the survival of 5HT neurons. In addition, these experiments have shown that not only the number of surviving neurons increased but also a significant increase in cell body size was observed (Fig. 3A,D) using image analysis.

As described above, in co-cultures, SC exerted a positive effect on serotoninergic neuron survival, accompanied by a significant increase in the length and branching processes $\left(\operatorname{Pr}_{-1}=128 \mu \mathrm{m}\right)$.

Figures 2, 3D and 4F show that, in the presence of SC, the length of neurites was four times as long as in controls and two times as long as those cultured with growth factors. Moreover, their length was also increased with more branch points compared to those 5-HT neuron cultures without SC (Figure 3A-E). Therefore, the results indicate that SC promote an increase in axonal and dendritic extension.
Effect of SC conditioned medium (CM) on serotoninergic neuron survival and morphology

To determine whether SC supported serotoninergic neuron survival through a release of soluble factors, CM was tested for a neurotrophic effect on serotoninergic neurons. Figure 1 shows that these cultures presented an increase in the number of 5-HT neurons (178 vs 40 per coverslip $\mathrm{P}<0.05$ ), accompanied by an evident and dense axonal and dendritic outgrowth (Fig. 3E and 4D).

In all the different experimental conditions, the 5HT neurons in culture did not express the low affinity NGFr, while SC were always NGFr positive.

\section{DISCUSSION}

In the present work we demonstrate that postnatal SC have the capacity to promote the survival and growth of embryonic cultured rhomboencephalic serotoninergic neurons. This property is probably mediated via soluble trophic factors, considering that the same results were obtained when the cultures of 5-HT neurons were co-cultured with SC or incubated with a conditioned medium derived from SC cultures. SC and their trophic factors have a remarkable effect not only on the survival of the serotoninergic neurons but also on their axonal and dendritic outgrowth, increasing their number and enhancing their length. Often the axonal branching was clearly directed toward the surrounding SC, perhaps indicating a particular tropism of the growing neuritic arborization in the direction of the cells that produce the trophic factors.

We obtained similar results incubating the 5-HT neurons cultures with NGF or with IGF-I. NGF, besides its well known activity on the sympathetic ganglion cells (Levi-Montalcini and Angeletti, 1968; Thoenen et al., 1971; Snider et al., 1988) has a relevant trophic effect also on basal forebrain cholinergic neurons and on sensory neurons, increasing the number of surviving neurons, the total length of neurites and the number of branching points ( Gnahn et al, 1983; Hefti et al., 1985; Hagg et al., 1989; Holtzman et al., 1995; Gavazzi et al., 1999). IGF-I and IGF-II stimulate the differentiation of dopaminergic neurons in culture (Knusel et al., 1990), regulating the growth of 5-HT and tyrosine hydroxylase neurons (Liu and Lauder, 1992), 
A)<smiles>CCC(C)C</smiles><smiles>CC(C)CCCCCC(C)C</smiles>

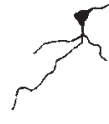

B)

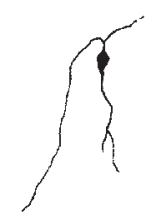

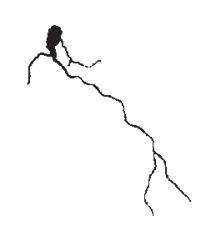<smiles>CNC(=S)C(C)(C)C</smiles>

C)

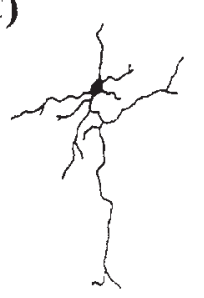

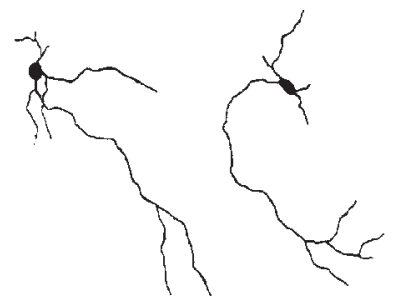

D)
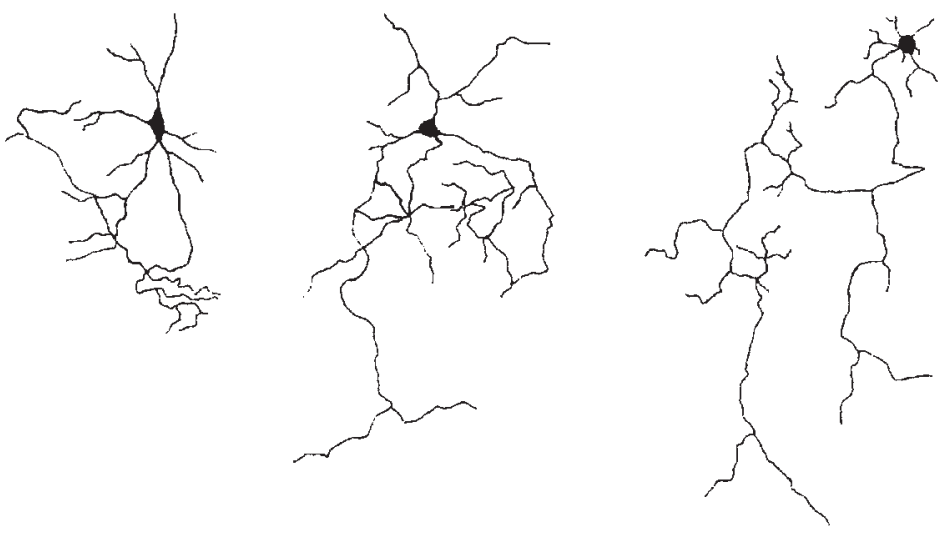

E)
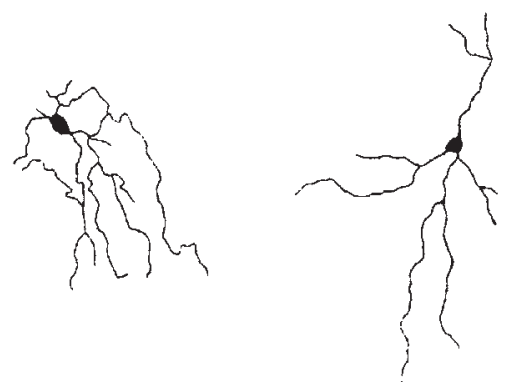

and neurite outgrowth in cultured motor, sensory, sympathetic, cortical neurons, and neuronal differentiation of stem cells (Brooker et al., 2000). Moreover, IGF-I rescues SC from apoptosis (Delaney $e t$
Fig. 3 - Camera lucida drawings of representative serotoninergic neurons in different conditions. Control cultures of serotoninergic neurons (A) showed a short neuritic and dendritic arborization. In the presence of NGF (B) and IGF-I (C), the cultures of serotoninergic neurons exhibited a greater complexity of neurite and dendritic outgrowth than in controls. In co-cultures with SC (D), serotoninergic neurons showed a significant increase in the length and branching of processes and in the cell body size (data not shown). In the presence of $\mathrm{CM}$ (E), serotoninergic neurons showed an increase in neuritic and dendritic outgrowth with a high degree of complexity and an increase in the cell body size, in analogy to that observed in co-cultures with SC.

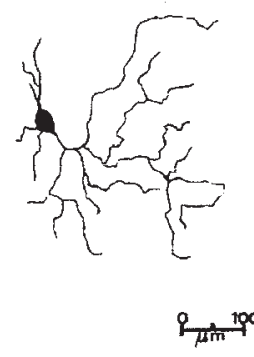

al.,1999) and enhances the formation of regenerated axons in SC implants if it is combined with Platelet-Derived Growth Factor (Oudega et al., 1997). The results of our study demonstrate that 

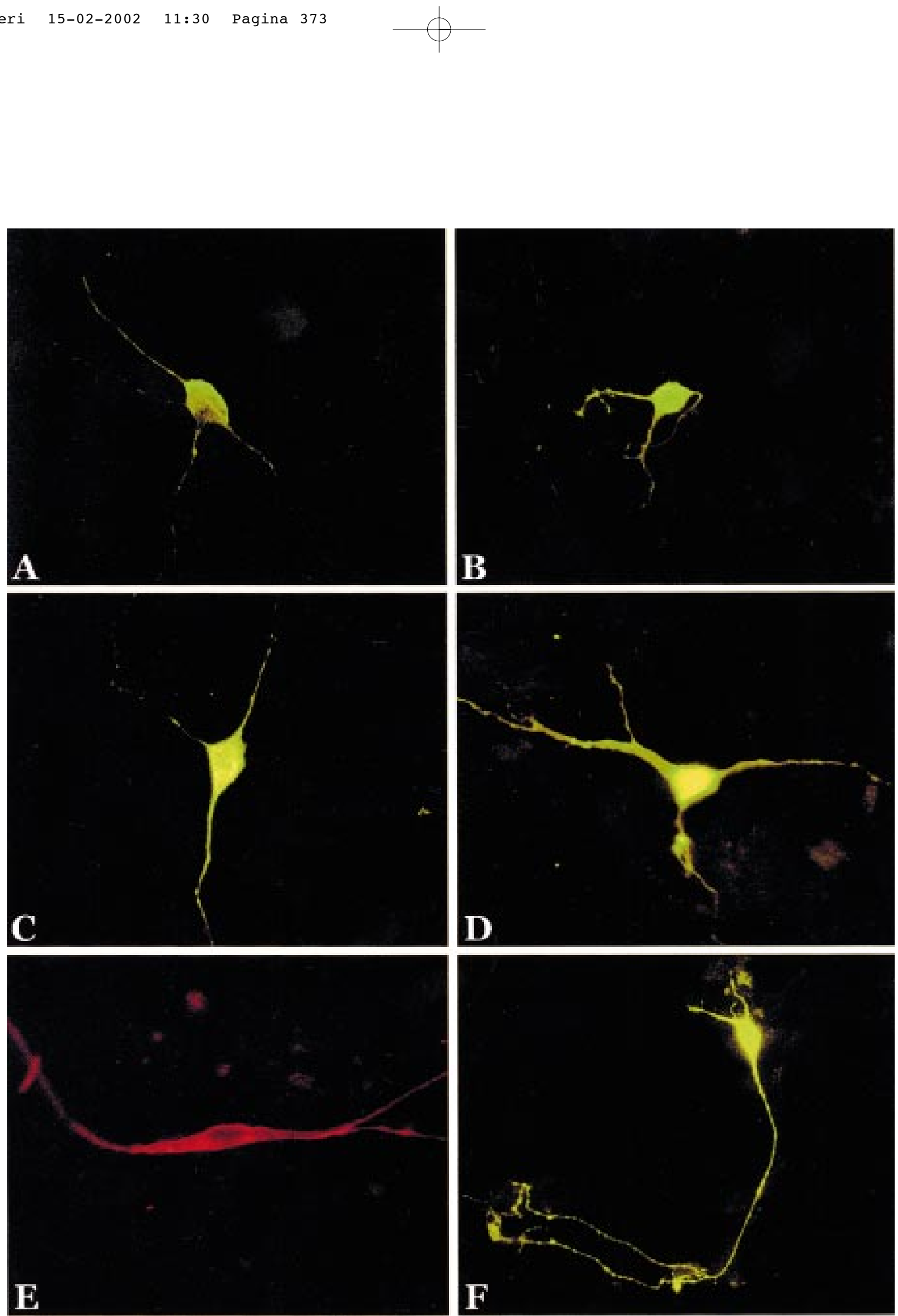

Fig. 4 - Fluorescence photomicrograph showing anti-serotonin immunocytochemical staining of neurons in different culture conditions. A) 5-HT positive neurons observed in control culture. B) 5-HT positive neurons grown in the presence of NGF (50 $\mathrm{ng} / \mathrm{ml})$. C) 5-HT positive neurons grown in the presence of IGF-I $(10 \mathrm{ng} / \mathrm{ml})$. D) 5 -HT neurons grown in the presence of CM from SC. E) anti-NGFr positive SC and 5-HT neurons (F) both grown in the same co-culture. 
NGF has a significant effect on the survival of serotoninergic neurons while the effect of IGF-I was less pronounced and not statistically significant. Conversely, both trophic factors had the same positive effect on neuritic and dendritic arborization, resulting in a higher degree of complexity of dendritic branching. Although effective, the influence of NGF or IGF-I on survival and neurite outgrowth of 5-HT neurons was less pronounced than that obtained with SC or CM obtained from SC cultures. All these data seem to suggest that the positive effect of SC cultures on 5-HT cultured neurons is mediated through trophic factors, such as NGF or IGF-I: the more efficacious activity of SC cultures might be due to a larger production of a single trophic factor or, more probably, to the secretion of numerous trophic substances which could have a synergic and additive effect on the target cell. It is possible that the factors released by SC cultures act as substratebound agents promoting neurite outgrowth. It is known that the RN22 Scwannoma secretes agents which bind to tissue culture substrates to promote neurite outgrowth. According to this, SC could release a substrate-bound factor increasing 5-HT neuron attachement rather than survival. SC have been in fact demonstrated to have the capacity to produce not only NGF (Henderson et al., 1993) and IGF-I (LeRoith, 1993), but also Epidermal Growth Factor (EGF) (Morrison et al., 1987, 1988), BDNF (Koliatsos et al., 1993), acidic and basic Fibroblast Growth Factor (aFGF and bFGF) (Morrison, 1986, 1988; Walicke et al., 1986; Murphy et al., 1990) and Ciliary Neurotrophic Factor (CNTF) (Sendtner et $a l ., 1994)$. It remains to be shown which trophic factors are produced by SC in the experimental conditions that we set up, considering that the type and amount of trophic substances secreted change in relation to the particular enviroment and, in particular, in relation to the target.

Neuron-glia interactions appear to be of main relevance not only during embryogenesis and the postnatal period but also during the process of degeneration and regeneration of the nervous system. Astrocytes more than fibroblasts have the capacity to facilitate neurite outgrowth of serotoninergic neurons (Lieth et al., 1990), and in coculture systems, where astrocytes and neurons grow together in the same enviroment but not in direct contact, it has been demonstrated that the regulation of axonal sprouting is mediated via a diffusible factor produced by astrocytes (Qian et al., 1992). The expectation behind the studies on the neuron-glia relationship is that, by improving our knowledge of the mechanisms of the trophic effect on neuronal survival and growth, it could be, at least theoretically, possible to enhance regenerative and possibly to decrease degenerative processes of the nervous system (Terenghi, 1999). The use of neurotrophic factors has been suggested in neurological disorders such as Alzheimer's disease and Parkinson's disease and, in fact, the data of this study support their use in degenerative diseases of the CNS involving serotoninergic neurons of the raphe, such as progressive supranuclear palsy (Holtzman et al., 1994).

Given the remarkable capacities of regeneration and recovery of the PNS, and considering that the process is at least partially mediated by the activity of SC, grafts of SC cultures have been made to mammalian brain or spinal cord in order to promote axonal regeneration (Kromer and Cornbrooks, 1985; Paino and Bunge, 1991; Bunge, 1991, 1994; Xu et al., 1994). Similary, Aguayo et al. (1985) have shown that SC are essential elements in trophic support of central axon regrowth in peripheral nerve grafts. It appears, therefore, reasonable to utilize SC as a source of neurotrophic factors, taking into account that it is now possible to obtain a large number of SC in cultures (Rutkowski et al., 1992) and that SC can be transplanted in nervous tissue (Tuszynski et al, 1998). Our study adds further data on the capacity of postnatal SC to promote survival and growth of CNS neurons, particularly serotoninergic neurons, but more effort is needed to precisely clarify the nature of the trophic factors produced by $\mathrm{SC}$ and their mechanism of action on the target cells of the CNS.

\section{ACKNOWLEDGEMENTS}

The present study was supported in part by grants from the Italian National Research Council (C.N.R.) n. 201.19.1 and 97.04542.CT04. The authors would like to thank Mr. Marco Castoldi for expert technical assistance.

\section{REFERENCES}

Aguayo A.J.: Axonal regeneration from injured neurons in the adult mammalian central nervous system. In Synaptic 
Plasticity, (Ed. CW Cotman), Guilford Press, New York, 457484, 1985.

Banker G.A.: Trophic interaction between astroglial cells and hippocampal neurons in culture. Science 209, 809-810, 1980.

Barde Y.A.: Purification of a new neurotrophic factor from mammalian brain. EMBO J. 1(5), 549-553, 1982

Barde, Y.A.: Trophic factors and neuronal survival. Neuron 2, 1525-1534, 1989

Beck K.D., Knusel B., and Hefti F.: The nature of the trophic action of Brain-Derived Neurotrophic Factor, des(1-3) Insulin-Like Growth Factor-1, and basic Fibroblast Growth Factor on mesencephalic dopaminergic neurons developing in culture. Neuroscience 52, 855-866, 1993.

Brockes J.P., Field K.P., and Raff M.C.: Studies on cultured rat Schwann cells. I. Establishment of purified populations from cultures of peripheral nerves. Brain Res. 165, 105-118, 1979.

Brooker G.J., Kalloniatis M., Russo V.C., Murphy M. Werther G.A., and Bartlett P.F.: Endogenous IGF-I regulates the neuronal differentiation of adult stem cells. J. Neurosci. Res. 59(3), 332-341, 2000.

Bunge R.P.: Schwann cells in central regeneration. Ann. New York Acad. Sci. 633, 29-233, 1991.

Bunge R.P.: The role of the Schwann cell in trophic support and regeneration. J. Neurol. 241, S19-S21, 1994.

Collier T.J., and Martin P.N.: Schwann cells as a source of neurotrophic activity for dopamine neurons. Exp. Neurol. 124, 129133, 1993.

Collier T.J., Sortwell C.E., and Daley B.F.: Diminished viability, growth, and behavioral efficacy of fetal dopamine neuron grafts in aging rats with long-term dopamine depletion: an argument for neurotrophic supplementation. J. Neurosci. 19, $5563-5573,1999$

Dahlstrom D.A., and Fuxe K.: Evidence for the existence of monoamine-containing neurons in the central nervous system. I. Demonstration of monoamines in the cell bodies of brain stem neurons. Acta Physiol. Scand. 62 Suppl. 232, 1-55, 1964

Delaney C.L., Cheng H.L., and Feldman E.L.: Insulin-like growth factor-I prevents caspase-mediated apoptosis in Schwann cells. J. Neurobiol. 41(4), 540-548, 1999.

Franke B., Bayatti N., and Engele J.: Neurotrophins require distinct extracellular signals to promote the survival of CNS neurons in vitro. Exp. Neurol., 165, 125-135, 2000.

Friedman H.C., Aguayo A.J., and Bray G.M.: Trophic factor in neuron-Schwann cell interaction. Ann. NY Acad. Sci. 883, 427-438, 1999.

Friedman W.J., Ernfors P., and Persson H.: Transient and persistent expression of NT-3/HDNF mRNA in the rat brain during postnatal development. J. Neurosci. 11(6), 1577-1584, 1991.

Frostck S.P., Yin Q., and Kemp G.J.: Schwann cells, neurotrophic factors, and peripheral nerve regeneration. Microsurgery, 18, 397-405, 1998.

Gavazzi I., Kumar R.D.C., McMahon S.B., and Cohen J.: Growth responses of different subpopulations of adult senso- ry neurons to neurotrophic factors in vitro. Europ. J. Neurosci. $11,3405-3414,1999$.

Gnahn H., Hefti F., Heumann R., Schwab M.E. and Thoenen H.: NGF-mediated increase of choline acetyltranferase (ChAT) in the neonatal rat forebrain: evidence for a physiological role of NGF in the brain. Dev. Brain Res. 9, 42-52, 1983.

Hagg T., Hagg F., Vahlsing H.L., Manthorpe M., and Varon S.: Nerve growth factor effects on cholinergic neurons of neostriatum and nucleus accumbens in the adult rat. Neuroscience. 30(1), 95-103, 1989.

Hatten M.E.: Neuronal regulation of astroglial morphology and proliferation in vitro. J. Cell Biol. 100, 384-396, 1985.

Hatten M.E., Lynch M., Rydel R.E., Sanchez J., Joseph-Silverstein J., Moscatelli D., and Rifkin D.B.: In vitro neurite extension by granule neurons is dependent upon astroglial-derived fibroblast growth factor. Dev. Biol. 125, 280-289, 1988.

Hefti F., Hartikka F., Eckenstein F., Gnahn H., Heumann R., and Schwab M.E.: Nerve growth factor increases choline acetyltranferase but not survival or fibers outgrowth of cultured fetal septal cholinergic neurons. Neuroscience. 14, 55-68, 1985.

Henderson C.E., Camu W., Mettling C., Gouin A., Poulsen K., Karihaloo M., Rullamas J., Evans T., McMahon S.P., Armanini M.P., Berkemeier L., Phillips H.S., and Rosenthal A.: Neurotrophin promote motor neurons survival and are present in embryonic limb bud. Nature. 363, 266-270, 1993.

Holtzman D.M., and Mobley W.C.: Neurotrophic factors and neurologic disease. West. J. Med. 161(3), 246-254, 1994.

Holtzman D.M., Kilbridge J., Li Y., Cunningham E.T., Lenn N.J., Clary D.O., Reichardt L.F., and Mobley W.C.: TrkA expression in the CNS: Evidence of several novel NGF-responsive CNS neurons. J. Neurosci. 15, 1567-1576, 1995.

Hyman C., Hofer M., Barde Y.A., Juhasz M., Yancopoulos G.D., Squinto S.P., and Lindsay R.M.: BDNF is a neurotrophic factor for dopaminergic neurons of the substantia nigra. Nature, 350, 230-232, 1991

Hyman, C. Juhasz M., Jackson C., Wright P., Ip N.Y., and Lindsay R.M.: Overlapping and distinct actions of the neurotrophins BDNF, NT-3, and NT-4/5 on cultured dopaminergic and GABAergic neurons of the ventral mesencephalon. J. Neurosci. 14, 335-347, 1994.

Knusel B., Michel P.P., Schwaber J. and Hefty F.: Selective and nonselective stimulation of central cholinergic and dopaminergic development in vitro by nerve growth factor, basic fibroblast growth factor, epidermal growth factor, and the insulin-like growth factors. J. Neurosci. 10, 558-570, 1990

Koliatsos V., Clatterbuck R.E., Winslow J.W, Cayouette M.H., and Price D.L.: Evidence that brain-derived neurotrophic factor is a trophic factor for motor neurons in vivo. Neuron 10, 359-367, 1993.

Konig N., Wilkie M.B., and Lauder J.M.: Tyrosine hydroxylase and serotonin containing cells in embryonic rat rhombencephalon: a whole-mount immunocytochemical study. J. Neurosci. Res. 20, 212-223, 1988.

Kromer L.F., and Cornbrooks C.J.: Transplants of Schwann cell cultures promote axonal regeneration in the adult mam- 
malian brain. Proc. Natl. Acad. Sci. USA. 82(18), 6330-6334, 1985.

LeRoith D., Roberts C.T.J., and Werner H.: Insulin-like growth factors in the brain. In: Neurotrophic factors. S. Loughlin, J. Fallon, eds. Academic press, San Diego, pp. 391-414, 1993.

Levi-Montalcini R., and Angeletti P.U.: Nerve Growth Factor. Physiol. Rev. 48, 534-569, 1968.

Levi-Montalcini R.: The Nerve Growth Factor 35 years later. Science 237, 1154-1161, 1987.

Lieth E., McClay R., and Lauder J.M.: Neuronal-glial interactions: Complexity of neuriite outgrowth correlates with substrate adhesivity of serotoninergic neurons. Glia 3, 169-179, 1990.

Liu J.P., and Lauder J.M.: S-100 beta and insulin-like growth factor-II differentially regulate growth of developing serotonin and dopamine neurons in vitro. J. Neurosci. Res. 33, 248-256, 1992.

Longo F.M., Holtzman D.M., Grimes M.L., and Mobley W.C.: Nerve Growth Factor: actions in the peripheral and central nervous system. In: Neurotrophic factors. J. Fallon, and Loughlin S., eds. Academic, New York, pp.209-256, 1992.

Mayer E, Dunnet S.B., Pellitteri R., and Fawcett J.W.: Basic Fibroblast Growth Factor promotes the survival of embryonic ventral mesencephalic dopaminergic neurons. Effects in vitro. Neuroscience 56, 379-388, 1993.

Morrison R.S., Sharma A., DeVellis J., and Bradshaw R.A.: Basic Fibroblast Growth Factor supports the survival of cerebral cortical neurons in primary culture. Proc. Natl. Acad. Sci. USA, 83, 7537-7541, 1986.

Morrison R.S., Kornblum H.I., Leslie F.M., and Bradshaw R.A.: Trophic stimulation of cultured neurons from neonatal rat brain by Epidermal Growth Factor. Science 238, 72-75, 1987.

Morrison R.S., Keating R.F., and Moskal J.R.: Basic Fibroblast Growth Factor and Epidermal Growth Factor exert differential trophic effects on CNS neurons. J. Neurosci. Res. 21, 71-79, 1988 .

Muller H.W., and Seifert W.: A Neurotrophic Factor (NTF) released from primary glial cultures supports survival and fiber outgrowth of cultured hippocampal neurons. J. Neurosci. Res. 8, 195-204, 1982.

Mirsky R., and Jessen K.R.: The neurobiology of Schwann cells. Brain Pathol. 9, 293-311, 1999.

Munson J.B., Shelton D.L., and McMahon S.B.: Adult mammalian sensory and motor neurons: roles of endogenous neurotrophins and rescue by exoogenous neurotrophins after axotomy. J. Neurosci. 17, 470-476, 1997.

Murphy M., Drago J., and Bartlett P.F.: Fibroblast Growth Factor stimulates the proliferation and differentiation of neuronal precursor cells in vitro. J. Neurosci. Res. 25, 463-475, 1990.

Murphy P.G., Borthwick L.A., Altares M., Gauldie J., Kaplan D., and Richardson P.M.: Reciprocal actions of interleukin-6 and brain-derived neurotrophic factor on rat and mouse primary sensory neurons. Eur. J. Neurosci. 12, 1891-1899, 2000.
Oudega M., Xu X.M., Guenard V., Kleitman N., and Bunge M.B.: A combination of insulin-like growth factor-I and plateled-derived growth factor enhances myelination but diminishes axonal regeneration into Schwann cell grafts in the adult rat spinal cord. Glia 19(3), 247-258, 1997.

Paino C.L., and Bunge M.B.: Induction of axon growth into Schwann cell implants grafted into lesioned adult rat spinal cord. Exp. Neur. 114(2), 254-257,1991.

Purves D.: Body and Brain: A trophic theory of neuronal connections, Cambridge: Harvard Univ: Press, 1988.

Qian J., Bull M.S., and Levitt P.: Target-derived astroglia regulate axonal outgrowth in a region-specific manner. Dev. Biol. 149, 278-294, 1992.

Ruit K.G., and Snider W.D.: Administration or deprivation of nerve growth factor during development permanently alters neuronal geometry. J. Comp. Neurol. 314, 106-113, 1991.

Russel J.W., Cheng H.L., and Golovoy D.: Insulin-like growth factor-I promotes myelination of peripheral sensory axons. J. Neuropathol. Exp. Neurol. 59, 575-584, 2000.

Rutkowski J.L., Tennkoon G.L., and McGillicuddy J.E. Selective culture of mitotically active human Schwann cells from adult sural nerves. Ann. Neurol. 31(6), 580-586, 1992.

Sendtner M., Carroll P., Holtmann B., Hughes R.A., and Thoenen H.: Ciliary Neurotrophic Factor. J. Neurobiol. 25, 1436-1453, 1994

Snider W.D.: Nerve growth factor enhances dendritic arborization of sympathetic ganglion cells in developing mammals. J. Neurosci. 8, 2628-2634,1989.

Snider W.D., and Johnson E.M.: Neurotrophic molecules. Ann. Neurol. 26, 489-506,1989.

Stichel C.C., Hermanns S., Lausberg F., and Muller H.W.: Effects of Schwann cell suspension grafts on axon regeneration in subacute and chronic CNS traumatic injuries. Glia 28(2), 156-165, 1999.

Terenghi G.: Peripheral nerve regeneration and neurotrophic factors. J. Anat. 194, 1-14, 1999.

Thoenen H., Angeletti P.U., Levi-Montalcini R., and Kettler R.: Selective induction of tyrosine hydroxylase and dopamine betahydroxylase in rat superior cervical ganglia by Nerve Growth Factor. Proc. Natl. Acad. Sci. USA, 68, 1598-1602, 1971

Tuszynski M.H., Weidner N., McCormack M., Miller I., Powell H., and Conner J.: Grafts of genetically modified Schwann cells to the spinal cord: survival, axon growth, and myelination. Cell Transplant 7(2), 187-196, 1998.

Walicke P., Cowan W.M., Ueno N., Baird A., and Guillemin R.: Fibroblast Growth Factor promotes survival of dissociated hippocampal neurons and enhances neurite extension. Proc. Natl. Acad. Sci. USA, 83, 3012-3016, 1986.

Yuen E.C., Li Y., Mischel R.E., Howe C.L., Holtzman D.M., and Mobley W.C.: Neurotrophins and the neurotrophic factor hypothesis. Neuronal Notes 1, 3-7, 1996.

Xu X.M., Guenard V., Kleitman N., and Bunge M.B.: Axonal regeneration into Schwann cell-seeded guidance channels grafted into transected adult rat spinal cord. J. Comp. Neurol. 351, 145-160, 1995. 